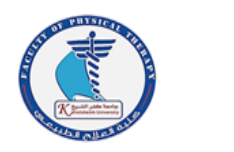

\title{
Kinesio Taping and Strength Recovery of Postnatal Abdominal Muscles after Cesarean Section
}

\author{
Hanan K. Mohamed ${ }^{1,}$ Amel M. Yousef ${ }^{1}$, Hossam-Eldin H. Kamel ${ }^{2}$, Khaled A. Oweda ${ }^{3}$, Gehan A. \\ Abd El-samea ${ }^{1}$
}

${ }^{1}$ Department of Woman's Health, Faculty of physical therapy, Cairo University, Egypt.

${ }^{2}$ Department of Obstetrics and Gynecology, Faculty of Medicine, El-Azhar University, Egypt.

${ }^{3}$ Department of Radiology, Faculty of Medicine, El-Azhar University, Egypt.

\author{
* Correspondence to \\ Hanan K. Mohamed \\ Department of Women \\ Health, Faculty of \\ Physical Therapy, Cairo \\ University, Egypt. \\ Tel:01125665868 \\ Email; hanan.karamallah. \\ mohamed@gmail.com
}

Published online: Dec 2020

\section{Introduction}

Pregnancy was considered a remarkable period in women's history, with many improvements affecting the musculoskeletal system (1). Relaxin hormonal release during pregnancy is referred to as one of the most important factors affecting mother's lax joints (2). The hormonal process that starts during pregnancy and continues in the postpartum period lead to

\begin{abstract}
:
Background: Physiotherapists in primary healthcare often encounter post-cesarean health problems as, it affects abdominal muscles strength. But there is little guidance in the literature for health professionals on the management of abdominal muscle strength recovery after cesarean section.

Objective: To assess the effect of Kinesio Taping on the recovery of abdominal muscle strength in postnatal women after cesarean section.

Methods: Forty cesarean section women participated in this study after two months of delivery. They were divided into two equal groups; Group(A) performed abdominal exercises and group(B) received Kinesio Taping (KT) in addition to performing abdominal exercises as group (A). The intervention sessions in both groups were twice per week for 8 weeks. The outcome measures were evaluating pre and post treatment via assessing the inter recti distance and abdominal muscle thickness for rectus abdominal muscles and external oblique muscles by using ultrasonography.

Results: The inter recti distance showed highly significant decrease $(p<0.0001)$ and highly significant increase $(\mathrm{p}<0.0001)$ in the thickness of rectus abdominis as well as external oblique muscles in both groups $(\mathrm{A} \& \mathrm{~B})$ post treatment. Comparison between both groups post treatment showed a highly significant difference $(\mathrm{p}<0.0001)$ in favor of group (B) in muscle thickness and inter recti distance.

Conclusion: Kinesio Taping (KT) helps in recovery of abdominal muscle after cesarean delivery.

Keywords Abdominal muscles, Cesarean section, Postnatal care, Kinesio Taping, Exercise

excessively weak and hypotonization abdominal muscles, making the ligaments and connective tissue softer and more elastic. These changes result in anatomical, physiological and biomechanical alterations. The muscular imbalance caused by overstretched weak abdominal muscles and powerful back muscles may lead to increased lordosis seen in women with a high number of pregnancies and a significant increase in joint laxity occurs during the last trimester of pregnancy (3).
\end{abstract}


Cesarean is one of the most common among abdominal surgery in women (4). Logically, it's not surprising that patients demonstrate core weakness after a cesarean delivery. The incision of the surgery cuts completely through the abdominal muscles. Although healing occurs, abdominal muscles are shown to be weaker post-surgery. Also, it is possible that with the new mother focused on their child, they will not engage in core strengthening activities, leaving them with a weakened core (5).

Therefore, these factors are liable for the lack of adequate support for the waist region, pain, disability and negatively effects on health-related quality of life (6). As, many physiotherapy studies in the literature concentrated on the health issues generally seen in early period after the cesarean delivery (7).

Studies emphasized the importance of exercise within the postpartum period. It's known that postnatal exercises have several benefits such as alleviating the post-natal depression and increasing the overall wellbeing (8-9), preventing the diastasis of the rectus abdominis muscle (10), increasing cardiovascular endurance and bone mineral density, and stimulating weight loss (11-12).

Kinesio Taping (KT) is used in a wide variety of clinical and sport-related conditions, with reported benefits including: increases in muscle function, improvements in blood and lymph flow, reduced discomfort, joint support, and improved skin and proprioceptive stimuli(13).The appliance of KT is known to be a conservative treatment procedure sometimes referred to as having the ability to alleviate pain(14-15), influence of skeletal muscles and joints (6-17) and generally bring physiological changes to improve patient wellbeing (18).

In the literature there are reports showing modulations in muscle strength and motor efficiency after application of KT, the specific characteristics sought by the athletic community and the key subject of study in the fields of orthopedic and medical sports (19). These effects are defined as having to do with continuous tensioning of the skin by the tape, therefore activating the skins' mechanoreceptors and stimulating central nervous system modulatory mechanisms, thereby raising muscle excitability (20).

\section{Materials and Methods}

This study was a randomized control study, approved by the Research Ethical Committee P.T.REC/012/001968 of the Faculty of Physical Therapy, Cairo University, and administrated on 40 postpartum women, after 2 months of cesarean delivery. Subjects were recruited for eligibility from the gynecologic outpatient clinic at Al-Azhar
University Hospital. Their ages ranged from 25 to 35 years, and all were primipara which gave birth by cesarean delivery. Inclusion criteria were breast lactating women; body mass index (BMI) less than 30 $\mathrm{kg} / \mathrm{m}^{2}$; didn't receive regular abdominal exercise in last 6 months. Exclusion criteria were abdominal hernia; diastasis recti more than $2 \mathrm{~cm}$; multiple pregnancies; other abdominal operations and abdominal skin diseases.

The women were divided randomly into two groups by system of randomization. Eligible patients who were recruited on Saturday and Wednesday were assigned to the control group (A), and those on Sunday and Thursday were assigned to the study group(B). Both groups followed the same program of abdominal exercises; and only group (B) applied KT with the abdominal exercises. The groups received their treatment twice per week for 8 weeks. Every woman received a simple demonstration explaining the abdominal exercises and each one signed a consent to declare her agreement to take part during this study.

\subsection{Evaluative procedures}

Evaluations were carried out in both groups (A\&B) before and after the interventions (8 weeks). The assessor was blind about the group's assignment and wasn't involved within the treatment application.

2.1.1. Weight and height: It had been measured while the patient wearing a thin layer of clothing in order to determine the BMI according with the equation: $\mathrm{BMI}=$ $\frac{w e \lg h t(\mathrm{~kg})}{h e i g h t\left(\mathrm{~m}^{2}\right)} \mathrm{kg} / \mathrm{m}^{2}$ for both groups(A\&B).

2.1.2. Ultrasonography: This was done by same radiologist throughout the study using Philips HD15 Ultrasound healthcare device with L12-4 broadband linear array transducer applying frequency $16 \mathrm{~Hz}$ and 4- $6 \mathrm{~cm}$ depth, the same transducer of the ultrasound was located within the same abdominal position as in visual feedback to Comparison of the thickness of abdominal muscle in $\mathrm{cm}$ which can help to decide whether there is a clear order and relative size that could be used as a guideline for determining abdominal muscle imbalance. Normal muscle size symmetry was reported for several muscles and was useful for assessing abnormality in patients, but normal symmetry of the abdominal muscles has not been reported (21-22).

2.1.2.1. For measuring of abdominal muscle thickness: The participants assumed a supported and relaxed crook lying position. Ultrasound gel was freely applied to the areas of imaging to validate good sonic coupling between the transducer and skin. Then ultrasonic probe was placed perpendicular on intersection between 
umbilicus line level and mid intercostal line perpendicularly on it. The ultrasound image was captured at the end of expiration. Measuring was done first on right side then left side for the rectus abdominis and then for external oblique muscles.

2.1.2.2. For measuring inter recti distance (IRD): The participants assumed a supported and relaxed crook lying position. Ultrasound gel was applied liberally to the areas of imaging to confirm good sonic coupling between the transducer and skin. It was placed perpendicular to the linea alba, above the umbilicus (midway between the umbilicus and the xiphoid process), then below umbilicus (midway between the umbilicus and symphysis pubis). Focus and depth were adjusted to visualize the medial aspects of both recti. The hyperechoic connective tissues with the hypoechoic rectus abdominis muscles were identified to measure the IRD at the end of a normal expiration.

\subsection{Treatment procedures}

The two groups (A\&B) received their treatments twice per week for 8 weeks.

2.2.1. Abdominal exercise program: This program was applied in both groups (A\&B), illustrations of the exercises were provided, in order that the woman could repeat the same exercise program on other days as a home routine. The program includes:

2.2.1.1. Static abdominal, abdominal crunch, external oblique floor crunch and Pelvic bridging exercises, each exercise was repeated 15 times, 3 times daily and was increased by five repetitions each week throughout the study period. Time of hold equals to time of relaxation.

Static abdominal exercise: From crock lying position and arms at side of the body, woman was instructed to contract her abdominal muscles and press her lumbar region down, hold this contraction for 5 seconds, then relax for 5 seconds.

Abdominal Crunch: From crock lying position with hands crossed over the chest, woman was instructed to contract her abdominal muscles and lift her head and shoulder off the plinth (until the scapulae were just off the plinth), hold this position for five seconds, after that woman returned to the starting position, then she relaxed for five seconds.

External oblique floor crunch: From crock lying position with hands crossed over the chest, woman was instructed to contract her abdominal muscles, raise and rotate her trunk until she touches her left knee by her right elbow. This position was maintained for five seconds, after that woman returned to the starting position, then she relaxed for five seconds. The same procedure was repeated on the opposite side
2.2.1.2. Core strengthening exercise (Side bridge, Bird - dog and Plank exercise), each exercise was repeated 3 times with hold time 8 seconds then relax, the time of hold equals to the time of relaxation. It performed 3 times daily and was increased to be 5 repetition with increase time of hold time to 10 seconds from the beginning of ${ }^{3 r d}$ week and increased again to 7 repetitions with hold 15 seconds at the beginning of $5^{\text {th }}$ week until end of the study period. Time of hold equals to time of relaxation.

\section{Side bridge exercise:}

- Level (1): Side lying position on the right side supported by the right hip flexed 90 degrees and elbow flexed 90 degrees. This has been done on each side with hold time while breathing deeply.

- Level (2): Full side bridge, legs were extended and the top foot was placed in front of the lower foot for support. This has been done on each side with hold.

Bird - dog exercise: From quadribed position, the woman was asked to raise the right arm only and hold this position, then relax and raise the left leg only and hold then relax. Afterwards, she asked to raise both right arm and left leg simultaneously and hold the position. The same steps were repeated on the other side with the same sequence.

Pelvic bridging exercise: From crock lying position, woman raised the pelvis upward till be comfortable.

Plank exercise: Prone position and put the weight of their body on the elbows \& toes; then they lifted the body upward, the exercises has been done with 3 times repetitions and holding while breathing deeply.

2.2.2 Kinesio Taping (KT): It had been applied only to group (B). KT was applied first, then followed by the abdominal exercises, so as to gain advantage of the improved muscle recruitment. Before starting the treatment session, the abdominal area was cleaned with alcohol to clean skin before tape application as skin should be freed from oils and lotions.

Step one: Tape was applied using I band with a tension of $50 \%$ on cesarean incision when the woman was in supine position, this band used as a fulcrum for KT applied in step 1\&2, Fig. (1).

Step two: Tape was applied on rectus abdominal muscle using muscle technique from origin to insertion of the muscle with a tension between 15 and $25 \%$. Band was started on symphysis pubis with no tension, then the woman was asked to stretch the abdominal region by deep abdominal respiration, and band ends on xiphoid process. This technique was applied first on left side then on right side rectus abdominal muscle, Fig. (2).

Step three: Finally, KT was performed on the external oblique muscles. The procedure started with no tension 
from the bottom end of the $6-12$ th ribs, then the hip was placed in flexion and rotation to the opposite direction and the band was performed on pubic bone with a tension between 15 and $25 \%$ [24]. This was applied first on left side then on the right side external oblique muscle, Fig. (3).

The woman rested for ten minutes after the tape application for allowing the tape to gain full adhesive strength then performed the abdominal exercises then. The tape was applied for three days and then removed for one day and reapplied for an additional 3 days (23). To remove the tape from the woman, they were instructed that it's easier to do when they had bathed or the tape was moist. It had been best to remove from the top down. This would be within the direction of the hair and can limit discomfort.

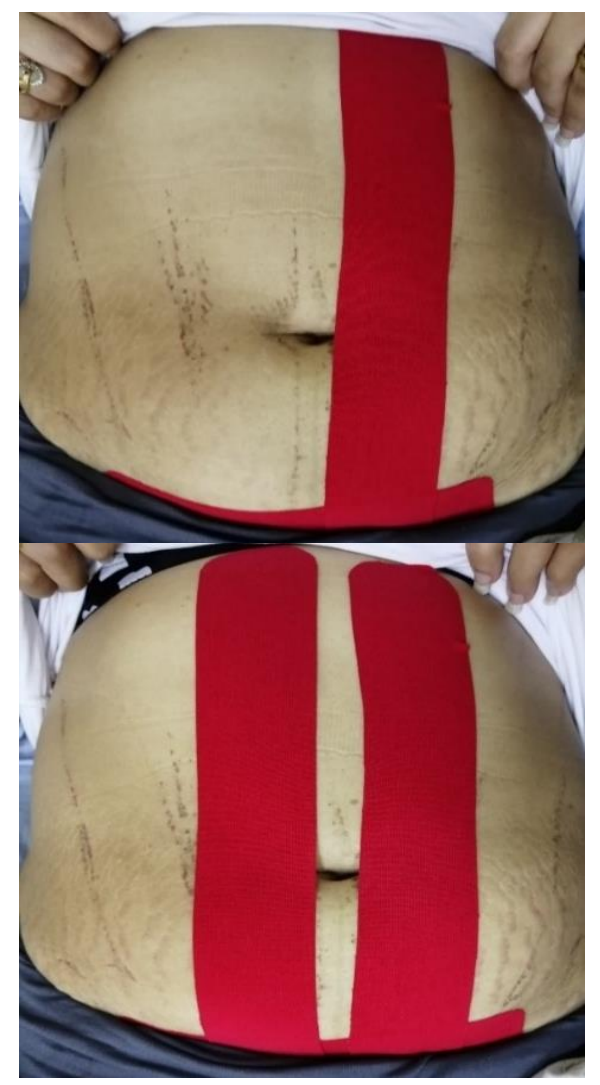

Fig. (2): Step two: KT applied on rectus abdominal muscle.

\section{Statistical analysis}

The collected data were statistically analyzed by using SPSS ver. 23 (SPSS Inc., Chicago, IL, USA). Descriptive statistics in the form of mean, standard deviation, and percentage were used. A paired t-test was used for comparing within groups, and an independent samples t-test was used to test between groups. In addition, non-parametric test was used for the type of work. A significance level of 0.05 was used throughout all statistical tests; p-value $<0.05$ will indicate a significant result, and $\mathrm{p}<0.01$ will indicate a highly significant result.

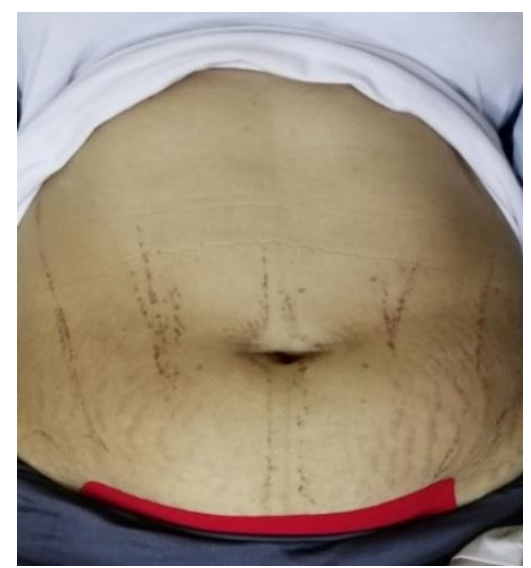

Fig. (1): Step one: Fulcrum tape on cesarean

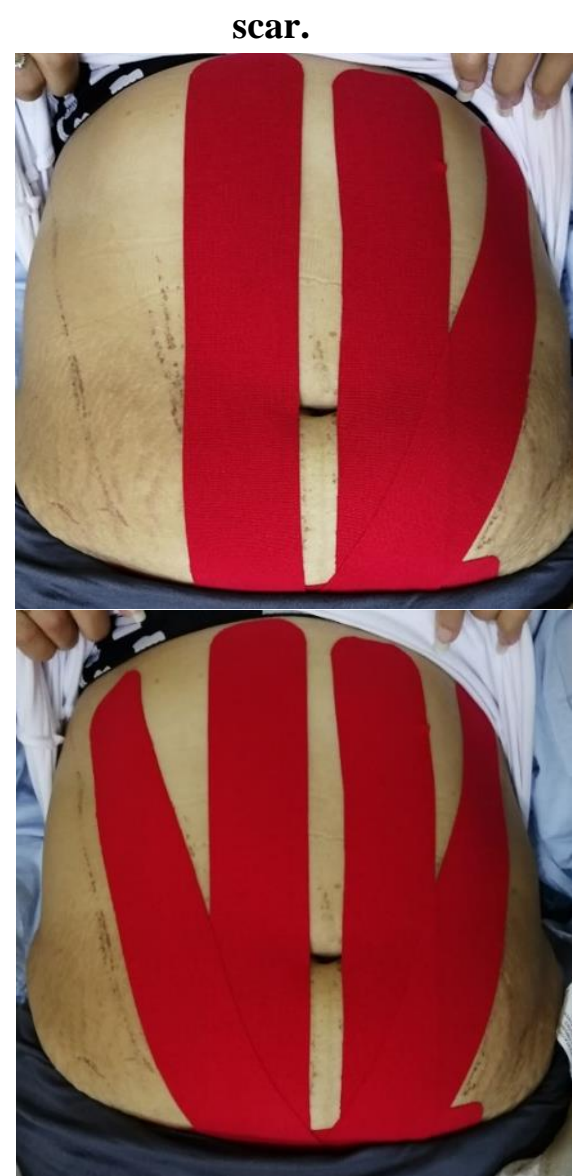

Fig.(3): Step three: KT applied on the right and left external oblique muscles.

\section{Results}

\subsection{Subject characteristics:}

The current study was conducted on 40 participants. They were assigned into two equal groups. Control group (A) consisted of 20 participants with mean age 
and BMI values of $28.47 \pm 2.12$ years and $27.4 \pm 1.19$ $\mathrm{kg} / \mathrm{m}^{2}$ respectively. Study group (B) consisted of 20 participants with mean age and BMI of 27.22 \pm 1.83 years and $27.3 \pm 1.57 \mathrm{Kg} / \mathrm{m}^{2}$ respectively. As indicated by the independent $t$ test, there were no significant differences ( $p>0.05)$ in the mean values of age and BMI between both tested groups (Table 1).

Table 1. Baseline characteristics of women in both groups.

\begin{tabular}{lccc}
\hline Variables & $\begin{array}{c}\text { Group (A) } \\
(\mathbf{n}=\mathbf{2 0})\end{array}$ & $\begin{array}{l}\text { Group (B) } \\
(\mathbf{n}=\mathbf{2 0})\end{array}$ & P value \\
\hline Age (yrs.) & $28.47 \pm 2.12$ & $27.22 \pm 1.83$ & $0.071^{\mathrm{NS}}$ \\
BMI $\left(\mathrm{Kg} / \mathrm{m}^{2}\right)$ & $27.4 \pm 1.19$ & $27.3 \pm 1.57$ & $0.073^{\mathrm{NS}}$ \\
\hline NS $\mathrm{P}>0.05=$ non-significant, $\mathrm{P}=$ Probability. & & \\
\end{tabular}

\subsection{Abdominal muscle thickness and inter recti distance:}

\subsubsection{Within group comparison:}

The abdominal muscle thickness was assessed by ultrasonography for the rectus abdominal muscles and external oblique muscle. Intergroup comparison showed a highly significant $(\mathrm{p}<0.05)$ increase in group (B) compared to group (A) in all parameters of abdominal muscle thickness. The intergroup comparison showed significant improvement for the right and left rectus abdominal muscles and right and left external oblique muscle in both groups; the improvement was in group (A) 7.3\%, 9.3\%, 16.16\% and $35 \%$; and in group (B) was $42.8 \%, 50 \%, 108 \%$ and $121 \%$, respectively. Also, intergroup comparison showed significant reduction $(\mathrm{p}<0.05)$ more in group (B) compared to group (A) of inter recti distance above and below umbilicus and the percentage of reduction was in group (A) $10.68 \%$ and $5.91 \%$; and in group (B) was33.68\% and 11.47, respectively.

\subsubsection{Between groups comparison:}

Considering the effect of the tested group (first independent variable) on thickness of right and left rectus abdominis muscle as well as external oblique muscles and the inter recti distance above and below umbilicus, Multiple pairwise comparison tests (Post hoc tests) revealed that the mean values of the "pre" test between both groups showed no significant differences . While, multiple pairwise comparison tests (Post hoc tests) revealed that there was significant difference of the mean values of the "post" test between both groups with $(\mathrm{p}=0.0001 *)$ and this significant reduction in favour to study group (B) than control group (A), (Table 2).
Table 2. Mean $\pm S D$ and $p$ values of US Rectus abdominis and External oblique muscles as well as inter recti distance Pre and Post-test at both groups.

\begin{tabular}{|c|c|c|c|c|}
\hline Variables & & $\begin{array}{c}\text { Group (A) } \\
(\mathbf{n}=\mathbf{2 0})\end{array}$ & $\begin{array}{c}\text { Group (B) } \\
(\mathbf{n}=\mathbf{2 0})\end{array}$ & P value* \\
\hline \multirow{4}{*}{$\begin{array}{l}\text { Inter recti } \\
\text { distance } \\
\text { above } \\
\text { umbilicus } \\
\text { (cm) }\end{array}$} & Pre-treatment & $1.31 \pm 0.11$ & $1.34 \pm 0.04$ & $0.33^{\mathrm{NS}}$ \\
\hline & Post-treatment & $1.17 \pm 0.12$ & $0.89 \pm 0.07$ & $0.0001^{\mathrm{s}}$ \\
\hline & Improvement $\%$ & $10.68 \%$ & $33.58 \%$ & \\
\hline & $\mathbf{P}$ value ${ }^{* *}$ & $0.0001^{\mathrm{s}}$ & $0.0001^{\mathrm{s}}$ & \\
\hline \multirow{4}{*}{$\begin{array}{l}\text { Inter recti } \\
\text { distance } \\
\text { below } \\
\text { umbilicus } \\
\text { (cm) }\end{array}$} & Pre-treatment & & & \\
\hline & Post-treatment & $1.75 \pm 0.04$ & $1.62 \pm 0.2$ & $0.0001^{\mathrm{s}}$ \\
\hline & Improvement $\%$ & $5.91 \%$ & $11.47 \%$ & \\
\hline & P value ${ }^{* *}$ & $0.0001^{\mathrm{s}}$ & $0.0001^{\mathrm{s}}$ & \\
\hline \multirow[t]{4}{*}{$\begin{array}{l}\text { Right Rectus } \\
\text { Abdominis } \\
\text { thickness }(\mathrm{cm})\end{array}$} & Pre-treatment & $0.41 \pm 0.013$ & $0.42 \pm 0.017$ & $0.425^{\mathrm{NS}}$ \\
\hline & Post-treatment & $0.44 \pm 0.008$ & $0.60 \pm 0.04$ & $0.0001^{\mathrm{s}}$ \\
\hline & Improvement $\%$ & $7.3 \%$ & $42.8 \%$ & \\
\hline & P value ${ }^{* *}$ & $0.0001^{\mathrm{s}}$ & $0.0001^{\mathrm{s}}$ & \\
\hline \multirow[t]{4}{*}{$\begin{array}{l}\text { Left Rectus } \\
\text { Abdominis } \\
\text { thickness }(\mathrm{cm})\end{array}$} & Pre-treatment & $0.43 \pm 0.02$ & $0.44 \pm 0.04$ & $0.341^{\mathrm{NS}}$ \\
\hline & Post-treatment & $0.47 \pm 0.04$ & $0.66 \pm 0.05$ & $0.0001^{\mathrm{s}}$ \\
\hline & Improvement $\%$ & $9.3 \%$ & $50 \%$ & \\
\hline & P value ${ }^{* *}$ & $0.0001^{\mathrm{s}}$ & $0.0001^{\mathrm{s}}$ & \\
\hline \multirow{4}{*}{$\begin{array}{l}\text { Right } \\
\text { External } \\
\text { Obliques } \\
\text { thickness }(\mathrm{cm})\end{array}$} & Pre-treatment & $0.198 \pm 0.011$ & $0.197 \pm 0.01$ & $0.885^{\mathrm{NS}}$ \\
\hline & Post-treatment & $0.23 \pm 0.04$ & $0.41 \pm 0.03$ & $0.0001^{\mathrm{s}}$ \\
\hline & Improvement $\%$ & $16.16 \%$ & $108 \%$ & \\
\hline & P value ${ }^{* *}$ & $0.0001^{\mathrm{s}}$ & $0.0001^{\mathrm{s}}$ & \\
\hline \multirow{4}{*}{$\begin{array}{l}\text { Left External } \\
\text { Obliques } \\
\text { thickness }(\mathrm{cm})\end{array}$} & Pre-treatment & $0.20 \pm 0.014$ & $0.194 \pm 0.006$ & $0.051^{\mathrm{NS}}$ \\
\hline & Post-treatment & $0.27 \pm 0.019$ & $0.43 \pm 0.034$ & $0.0001^{\mathrm{s}}$ \\
\hline & Improvement $\%$ & $35 \%$ & $121 \%$ & \\
\hline & $\mathbf{P}$ value ${ }^{* *}$ & $0.0001^{\mathrm{s}}$ & $0.0001^{\mathrm{s}}$ & \\
\hline \multicolumn{5}{|c|}{$\begin{array}{l}\text { Data were expressed as mean } \pm \text { standard deviation } \\
* \text { Inter-group comparison; } * * \text { intra-group comparison of the results pre- and post- } \\
\text { treatment. } \\
{ }^{\mathrm{NS}} \mathrm{P}>0.05=\text { non-significant, }{ }^{\mathrm{S}} \mathrm{P}<0.05=\text { significant, } \mathrm{P}=\text { Probability. }\end{array}$} \\
\hline
\end{tabular}

\section{Discussion}

The current research was aimed to testing the impact of the 8 weeks application of KT on postnatal abdominal muscle recovery after cesarean delivery. This was assessed by pre and post ultrasonography imaging comparing variations in the thickness of both rectus abdominis and external oblique muscles and a significant reduction of the intra-recti distance; as here the increasing of thickness in abdominal muscles means also gaining strength and power. Intervention 
for both groups began after 2 months (8 weeks) postnatal, as the abdominal muscles' ability to stabilize the pelvis against resistance declines during pregnancy and for a minimum8 weeks post birth(24).Furthermore, the intervention protocol in both groups extended for 8 weeks to realize muscle hypertrophy, which can't be recognized until 8 to 12 weeks after initiating resistance training (25).

Group (A), who received abdominal exercises only, showed significant improvement within the measured parameters, because abdominal exercises help to strengthen and control muscles and improve their tone, which reduces the strain load on the linea alba (26).

Group (B), who received the KT additionally to abdominal exercises, showed both intragroup and intergroup significant improvement within all the measured parameters. This augmented improvement can be due to the higher muscle overload intensities that cause the greater strength gains (27) resulted from combining the KT application with the abdominal muscle exercises.

Abdominal exercises focus should get on abdominal re-engagement, activation and reinforcement, abdominal muscles need to be strengthened to restore full functionality and providing maximum support and mobility to the core, it's better if done many times a day, rather than one time a day or once per week, the more regularly they're conducted, the more body sensitivity is restored, facilitating quicker, more efficient abdominal healing and strengthening; which rebuild and restore core and pelvic stability for a solid foundation to prevent future injury or discomfort (28) that could explain the gained results in the present study. Exercise promotes muscle hypertrophy and gains in muscle strength by stimulating myofibrillar muscle protein synthesis and inhibiting muscle protein breakdown (29-30).

The results of this present study in group (B) were supported by several theories on how KT facilitates neuromuscular healing. The first theory; is that KT directly applied on skin provides blood flow by increasing the interstitial area and thus improves muscle activation. The second theory; involves activation of motor unit by stimulation of cutaneous receptors by tactile stimuli given by KT (31). This tactile stimulation of the skin by taping affects the central nervous system's excitability and also correlates with motor function. Tactile input through the skin is known to be more than adequate to alter muscle power(32).In addition, some studies find increased recruitment of motor units and an increased bioelectrical activity immediately after application KT(33) and increased muscle strength(25). As the exact time span when application of KT starts to produce the desired effect on muscle strength and the length of this effect are still unknown. KT's effect on muscles is thought to be the reflex mechanism on the nervous system (33).

The study of Gürşen and colleagues reported an increase in abdominal muscle strength and endurance, and decrease in intensity of pain, an improvement in waist and umbilical circumferences and a decrease in disability in postnatal women who obtained KT with exercise (34); are agreed with the findings of the present study in which the combination of both exercise and KT is successful for acquiring abdominal muscle thickness which means gaining abdominal strength and decrease in inter recti distance.

S1upik et al. also determined the effect of KT on the bioelectric activity of the vastus medialis muscle, which showed an improvement in the electromyographic activity after 24 hours of KT, as well as the maintenance of the motor function after 2 days of KT and the removal of the tape (35), thus this results could explain the effect of applying KT in increasing the strength of the muscles within the present study. Kim and Lee also registered an improvement in muscle torque after applying KT to quadriceps and hamstring, as assessed by isokinetic equipment (36).

However, Fu et al. Disagreed with the results of the present study as they examined the effect of KT by isokinetic dynamometry on the strength of quadriceps of healthy athletes and concluded that no substantial difference in muscle strength was observed either immediately after taping or after 12 hours of taping, indicating that the muscle strength of quadriceps and hamstrings was uniform in healthy people (37). And also, Serrão et al. reported the muscle activation after KT during squatting exercises wasn't significantly different for different directions of kinesiology tape application (38).

This study got several limitations. First was the inability to use other objective methods such as electromyographic measurement or isokinetic dynamometer to determine abdominal muscles activation, strength and endurance. Although isokinetic dynamometer is usually recommended as an objective assessment method, it's still very expensive. Absence of sham taping was also another limitation of this study. However, it'd be better to combine exercise and KT and compare with exercise group and the sham group. Absence of follow up was also a limitation during this study.

\section{Conclusion}

Based on the study findings, it concluded that KT added to exercise is a more effective method than exercise alone to reinforce abdominal re-training in women who had cesarean delivery. This method can 
include in postnatal physiotherapy programs to accelerate the effectiveness of exercises which can improve the standard and efficiency of the postnatal health care. So, the results of this study could give insight to obstetricians, physiotherapists and other health care professionals who plan postnatal health care and rehabilitation programs. However, further studies with larger sample sizes, other regulations, multipara women, other objective evaluation methods, mixed two or more objective methods and long-term follow-ups should be planned to research the chronic effects of KT on abdominal strength recovery in women after cesarean delivery.

\section{Conflict of Interests}

The authors declare no conflict of interest.

\section{References}

1. Artal R, O'toole M. Guidelines of the American College of Obstetricians and Gynecologists for exercise during pregnancy and the postpartum period. British Journal of Sports Medicine. 2003 ;37(1):6-12.

2. Kouhkan S, Rahimi A, Ghasemi M, Naimi S, Baghban A. Postural changes during first pregnancy. Journal of Advances in Medicine and Medical Research. 2015, 23:744-53.

3. Been, E., and Kalichman, L. Lumbar lordosis. The Spine Journal. 2014;14(1): 87-97.

4. Mathai M, Hofmeyr G, Mathai N. Abdominal surgical incisions for caesarean section. Cochrane Database of Systematic Reviews.2013;(5): CD004453.(Doi:10.1002/14651858.CD004453).

5. Vermelis J, Wassen M, Fiddelers A, Nijhuis J, Marcus M. Prevalence and predictors of chronic pain after labor and delivery. Current Opinion in Anesthesiology. 2010; 23(3):295-9.

6. Gutke A, Lundberg M, Östgaard H, Öberg B. Impact of postpartum lumbopelvic pain on disability, pain intensity, health-related quality of life, activity level, kinesiophobia, and depressive symptoms. European Spine Journal. 2011 ;20(3):440-8.

7. Kayman-Kose S, Arioz D, Toktas H, Koken G, Kanat-Pektas M, Kose M, Yilmazer M. Transcutaneous electrical nerve stimulation (TENS) for pain control after vaginal delivery and cesarean section. The Journal of Maternal-Fetal \& Neonatal Medicine. 2014; 27(15):1572-5.

8. Norman E, Sherburn M, Osborne R, Galea M. An exercise and education program improves wellbeing of new mothers: a randomized controlled trial. Physical Therapy. 2010; 90(3):348-55.

9. Swedish Research Council. Physical Activity in The Prevention and Treatment of Disease. Swedish National Institute of Public Health, Östersund,2010, Sweden.www.fhi.se/en.
10. Adeniyi A, Ogwumike O, Bamikefa T. Postpartum exercise among Nigerian women: issues relating to exercise performance and self-efficacy. ISRN Obstetrics and Gynecology.2013; 294518. (Doi:10.1155/2013/294518).

11. Mottola M. Exercise in the postpartum period: practical applications. Current Sports Medicine Reports. $2002 ; 1(6): 362-8$.

12. Nascimento S, Pudwell J, Surita F, Adamo K, Smith G. The effect of physical exercise strategies on weight loss in postpartum women: a systematic review and meta-analysis. International Journal of Obesity. 2014;38(5):626-35.

13. Bicici S, Karatas N, Baltaci G. Effect of athletic taping and kinesiotaping ${ }^{\circledR}$ on measurements of functional performance in basketball players with chronic inversion ankle sprains. International Journal of Sports Physical Therapy. 2012;7(2):154.

14. Donec V, Kriščiunas A. The effectiveness of Kinesio Taping ${ }^{\circledR}$ after total knee replacement in early postoperative rehabilitation period. A randomized controlled trial. Eur J Phys Rehabil Med. 2014;50(4):363-71.

15. Şimşek H, Balki S, Keklik S, Öztürk H, Elden H. Does Kinesio taping in addition to exercise therapy improve the outcomes in subacromial impingement syndrome? A randomized, doubleblind, controlled clinical trial. Acta Orthopaedica et Traumatologica Turcica. 2013;47(2):104-10.

16. Akbaş E, Atay A, Yüksel I. The effects of additional kinesio taping over exercise in the treatment of patellofemoral pain syndrome. Acta Orthopaedica et Traumatologica Turcica. 2011;45(5):335.

17. Yeung S, Yeung E, Sakunkaruna $Y$, Mingsoongnern S, Hung W, Fan Y, Iao H. Acute effects of kinesio taping on knee extensor peak torque and electromyographic activity after exhaustive isometric knee extension in healthy young adults. Clinical Journal of Sport Medicine. 2015;25(3):284-90.

18. Castro-Sánchez A, Lara-Palomo I, MataránPeñarrocha G, Fernández-Sánchez M, SánchezLabraca N, Arroyo-Morales M. Kinesio Taping reduces disability and pain slightly in chronic nonspecific low back pain: a randomised trial. Journal of Physiotherapy. $2012 ; 58(2): 89-95$.

19. Vercelli S, Sartorio F, Foti C, Colletto L, Virton D, Ronconi G, Ferriero G. Immediate effects of kinesiotaping on quadriceps muscle strength: a single-blind, placebo-controlled crossover trial. Clinical Journal of Sport Medicine. 2012; 22(4):319-26.

20. Gomez-Soriano J, Abián-Vicén J, Aparicio-García C, Ruiz-Lázaro P, Simón-Martínez C, Bravo- 
Esteban E, Fernández-Rodríguez J. The effects of Kinesio taping on muscle tone in healthy subjects: a double-blind, placebo-controlled crossover trial. Manual therapy. 2014;19(2):131-6.

21. Hides J, Richardson C, Jull G. Multifidus muscle recovery is not automatic after resolution of acute, first-episode low back pain. Spine. 1996; 21(23):2763-9.

22. Hides J, Stokes M, Saide M, Jull G, Cooper D. Evidence of lumbar multifidus muscle wasting ipsilateral to symptoms in patients with acute/subacute low back pain. Spine. 1994; 19(2):165-72.

23. Kase K. Clinical therapeutic applications of the Kinesio (! R) taping method. Albuquerque. 2003.

24. Gilleard W, Brown J. Structure and function of the abdominal muscles in primigravid subjects during pregnancy and the immediate postbirth period. Physical Therapy. 1996 ;76(7):750-62.

25. Häkkinen, K., Newton, R. Gordon, S., McCormick, M., Volek, J., Nindl, B., Gotshalk, L., Campbell, W., Evans, W., Häkkinen, A. and Humphries, B. Changes in muscle morphology, electromyographic activity, and force production characteristics during progressive strength training in young and older men. The Journals of Gerontology Series A: Biological Sciences and Medical Sciences, 1998, 53(6): B415-B423.

26. Chiarello C, Falzone L, McCaslin K, Patel M, Ulery K. The effects of an exercise program on diastasis recti abdominis in pregnant women. Journal of Women's Health Physical Therapy. 2005; 29(1):11-6.

27. Steib S, Schoene D, Pfeifer K. Dose-response relationship of resistance training in older adults: a meta-analysis. Med Sci Sports Exerc. 2010; 42(5):902-14.

28. Swanson S. Abdominal muscles in pregnancy and the postpartum period. International Journal of Childbirth Education. 2001;16(4):12.

29. Brook M, Wilkinson D, Phillips B, PerezSchindler J, Philp A, Smith K, Atherton P. Skeletal muscle homeostasis and plasticity in youth and ageing: impact of nutrition and exercise. Acta Physiologica. 2016;216(1):15-41.

30. Phillips S. A brief review of critical processes in exercise-induced muscular hypertrophy. Sports Medicine. 2014;44(1):71-7.

31. de Almeida Lins C, Neto F, de Amorim A, de Brito Macedo L, Brasileiro J. Kinesio Taping ${ }^{\circledR}$ does not alter neuromuscular performance of femoral quadriceps or lower limb function in healthy subjects: Randomized, blind, controlled, clinical trial. Manual Therapy. 2013;18(1):41-5.

32. Riemann B, Lephart S. The sensorimotor system, part II: the role of proprioception in motor control and functional joint stability. Journal of Athletic Training. 2002;37(1):80.

33. Chang $\mathrm{H}$, Chou $\mathrm{K}$, Lin J, Lin C, Wang C. Immediate effect of forearm Kinesio taping on maximal grip strength and force sense in healthy collegiate athletes. Physical Therapy in Sport. 2010;11(4):122-7.

34. Gürşen $\mathrm{C}$, İnanoğlu $\mathrm{D}$, Kaya $\mathrm{S}$, Akbayrak $\mathrm{T}$, Baltac1 G. Effects of exercise and Kinesio taping on abdominal recovery in women with cesarean section: a pilot randomized controlled trial. Archives of Gynecology and Obstetrics. 2016; 293(3):557-65.

35. Słupik A, Dwornik M, Białoszewski D, Zych E. Wpływ ap- likacji. kinesiotapingu na aktywno's'c bioelektryczna, mie,'snia obszernego

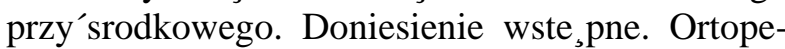
dia Traumatologia Rehabilitacja; 2007;6(6): 644651. (English abstract).

36. Kim H, Lee B. The effects of kinesio tape on isokinetic muscular function of horse racing jockeys. Journal of Physical Therapy Science. 2013;25(10):1273-7.

37. Fu T, Wong A, Pei Y, Wu K, Chou S, Lin Y. Effect of Kinesio taping on muscle strength in athletes - a pilot study. Journal of Science and Medicine in Sport. 2008;11(2):198-201.

38. Serrão, J., Mezêncio, B., Claudino, J., Soncin, R., Miyashiro, P., Sousa, E., Borges, E., Zanetti, V., Phillip, I., Mochizuki, L. and Amadio, A., Effect of 3 different applications of Kinesio Taping Denko® on electromyographic activity: inhibition or facilitation of the quadriceps of males during squat exercise. Journal of Sports Science \& Medicine,2016; 15(3):403. 